\title{
Impacts of Climate Variability on Tuber Crops in Guinea Savanna Part of Nigeria: A GIS Approach
}

\author{
A. Ayanlade, T.O. Odekunle \& O.O.I. Orimoogunje \\ Department of Geography \\ Obafemi Awolowo University Ile-Ife, Nigeria \\ E-mail: sinaayanlade@yahoo.co.uk, odeyemitheophilus@yahoo.com, orimoogunje2@yahoo.com
}

This study is part of a research project funded by Council for the Development of Social Science Research in Africa (CODESRIA). The Author thank the Space Application and Environmental Science Laboratory, coordinated by Prof. Salami A.T., of Institute of Ecology, Obafemi Awolowo University, Ile-Ife, Nigeria, for the scientific contribution to training activities and fellowship grant support.

\begin{abstract}
The study developed a Geographical Information Systems (GIS) database and mapped inter-annual changes in tuber crop yield as a response to inter-annual rainfall variability in the Guinea Savanna ecological zone of Nigeria. It also related the spatiotemporal variability in rainfall with tuber yields. Two major tuber crops were used for this study (i.e. Cassava and Yam). Kriging and other GIS techniques were used for the spatial analysis. Also, correlation and regression analysis were carried out on the dataset. The study fund out that rainfall varies from one year to the other $(550 \mathrm{~mm}$ to $2987 \mathrm{~mm})$. The results showed that there were significant relationship between tuber yield and total rainfall ( $r=0.68$, at $\mathrm{p}<0.05$ for cassava; and $\mathrm{r}=0.62$, at $\mathrm{p}<0.05$ for yam). The study concluded that geospatial techniques are ample tools that should be explored further for realistic assessment of the effects on climate of farming activities.
\end{abstract}

Keywords: Climate Variability, Tuber crops, GIS, Nigeria

\section{Introduction}

Several studies on the impacts of climate variability on crops yield have been carried out in different parts of the world by Intergovernmental Panel on Climate Change (IPCC) and other scholars. Some of these studies have shown significant impacts of climate variability on agricultural activities, especially during the last 40 -year period. Generally, rainfall regime is the most important climatic factor influencing agricultural activities particularly in the tropical region. Rainfall can vary considerably even within a few kilometres distance and on different time scale. This implies that crop yield is exceedingly variable over space and time. It has biggest effect in determining the crops that can be grown, the farming system, the sequence and timing of farming operations (Adejuwon, 2005). Rainfall can also be seen as the supplier of soil moisture for crops. The soil moisture supply, however, does not depend on rainfall alone, but also on various other factors concerned in the hydrological equation, such as evapotranspiration and surface run-off (IPCC, 2000). In many areas with alternating wet and dry seasons, the annual rainfall is less than the amount of the water that a crop well supplied with water would transpire during the growing season. In such circumstances, a fair depth of soil may be at field capacity fairly frequently during the immature phase of the crop, but later the mature crop may dry out the soil to the full depth of its rooting system, or a little deeper. This can have two effects on crops (Stern and Coe 1982). First, during the latter part of the growing season, insufficient soil moisture may restrict transpiration to well below the potential rate, with corresponding reduction in growth and yield. Second, after harvesting the crop, there will be a deep layer of soil which must be recharged to something approaching field capacity early in the following rains before satisfactory growth of the next crop can occur (Stern and Coe 1982). In the Guinea Savanna Ecological Zone of Nigeria, little systematic research has focused on the distribution patterns of the impacts of rainfall variability, in terms of mapping its spatiotemporal impact using the modern GIS techniques such as Kriging interpolation technique. There is need, however, for an integrated type of this GIS modeling system, to allow agricultural producer as well as policy makers to know the impact of spatio-temporal variation in rainfall on crop yield for better management, productivity and profitability. Therefore, this study is aimed at using GIS Kriging interpolation technique together with correlation and regression methods to examine and map the spatiotemporal impact of rainfall variability on crop yields in the Guinea Savanna Ecological Zone of Nigeria. 


\section{Study Area}

The Guinea Savanna Ecological Zone of Nigeria was selected for this research work because the area intensely produces tuber crops such as yam and cassava. Further, the large inter-annual variability of rainfall subjects the area to frequent dry spells that sometimes result in severe and widespread drought that impose serious socio-economic constraints (Buchanan and Pugh, 1955). Rainfall is the key climatic variable in the study area. Rainfall in the zone is largely seasonal and highly variable from year to year, with mean annual rainfall of between $1500 \mathrm{~mm}$ and $1800 \mathrm{~mm}$ in north and south respectively. The climate of the area is characterized with relatively high temperatures throughout the year. The average annual maximum temperature varies between $35^{\circ} \mathrm{C}$ and $31^{\circ} \mathrm{C}$ throughout the year while the average annual minimum temperature is between $23^{\circ} \mathrm{C}$ and $20^{\circ} \mathrm{C}$ (FAO, 2001). On the Jos plateau and the eastern highlands, altitude makes for relatively lower temperatures, with the maximum temperature of $28^{\circ} \mathrm{C}$ and minimum temperature of $14^{\circ} \mathrm{C}$ (FAO, 2001). Farming is generally rainfed and has the subsistence variety. Other crops grown include grains such as rice, wheat, soybeans, beans, maize and millet and tuber crops such as yam and cassava. Agriculture employs the larger percentage of the working population in the area, but agricultural landholdings are generally small. The average number of farm plots per household ranges between 3 and 30 plots and between 0.4 and 4.0 ha (FAO, 2002b). The predominant form of crop husbandry in this region is the rainfed cultivation of annual crops.

\section{Materials and Methods}

Tuber crop yields and rainfall data for 1970 to 2000 were used in this study and the data are for nine stations located in the study area. Data on annual tuber crop yield were obtained and were used for this study. The tuber crop data were collected for all the state within which the rainfall stations were located (Enugu, Yola, Makurdi, Kaduna, Jos, Shaki, Minna, Lokaga, and Ilorin). Rainfall data were collected from the archives of the Nigerian Meteorological Services, Oshodi Lagos. The crops used for this study are for the period 1970 to 2000. These thirty (30) years data were collected from annual collection of data on agricultural production through household sample surveys by the FOS, National Household Survey Capability Program (NHSCP), State Agricultural Programme and Central Bank (CBN) annual survey. Three spatial interpolation methods were chosen for this research work: Inverse Distance Weighting (IDW) method and the Spline (completely regularized) as the determinist methods; and Ordinary Kriging as the stochastic method. In order to analyze the interpolation quality, an evaluation by cross validation has been carried out. The three different spatial interpolation methods are then applied to estimate the missing value on the basis of the remaining observed ones. This process has been carried out on each rain station. For each interpolation test on the three methods, the rainfall observed values $Z(x)$ have been considered, the estimated values $\check{Z}(\mathrm{x})$, and the errors $\mathrm{e}(\mathrm{x})=\mathrm{Z}(\mathrm{x})-\check{Z}(\mathrm{x})$. The mean of the errors and its standard deviation was then calculated for each interpolation method. The statistical methods that were employed for this study include coefficient of variation, multiple correlation, regression and z-distribution chart. Coefficient of variation (CV) was used to determine rainfall variability. Although, there are many measures of variability, the two most widely used are the relative variability and the coefficient of variation. The latter measure is the more efficient for this research work. Therefore, $\mathrm{CV}$ was used to examine rainfall variability and to assess the sensitivity or response (i.e. to assess impact) of crop yield to variability in rainfall. It is a measure of dispersion given by:

\section{Co-efficient of variation $=($ Standard deviation $/$ mean $) * 100$.}

The mean and the standard deviations of the yields of tuber crop for each station are first calculated, and then the co-efficient of variation is determined as a percentage of the mean. The coefficient of variation (CV) is mathematically expressed as:

$$
\mathrm{CV}=\partial / \mathrm{R}_{\mathrm{f}} * 100 \%
$$

Where $\partial$, the standard deviation is defined by

$$
\partial=\left\{\sum\left(\mathrm{R}_{\mathrm{f}}-\mathrm{R}_{\mathrm{f}}^{\prime}\right)^{2}\right\} / \mathrm{N}
$$

Where $R_{f}$ is the annual rainfall for a given period, $R_{f}^{\prime}$ is the average annual rainfall and $N$ is number of variable.

To show the impacts of rainfall variability on tuber yield, z-distribution chart was adopted for this study. The tuber yield array was converted to a $z$-distribution format varying in magnitude from -3 to +3 . Hence, if the variations in tuber yield from one year to the other are caused by the variation in rainfall, then the impacts represent negative and positive anomalies of yield which was computed for each year. From this format, significant positive and significant negative impacts, separated by the normal yield level were discriminated. 


\section{Results and Discussions}

\subsection{Rainfall Variability}

The study found out that rainfall variability is very high in most parts of Northern Guinea Savanna (e.g Yola, Minna, and Kaduna) except Jos which has a unique pattern. Generally, the decadal mean rainfall values vary from $550 \mathrm{~mm}$ to $2987 \mathrm{~mm}$. The highest mean rainfall was during the third decade (1990-1999) with six interpolation silhouettes while the least was observed during the second decade (1980-1989) with four interpolation silhouettes. Figure.1 shows rainfall variability per decade in Guinea Savanna, part of Nigeria, from 1970 to 2000. As depicted in Figure 1a, rainfall gradually reduces from Southern Guinea Savanna to Northern Guinea Savanna during the period of 1970 -1979. Figure 1b however shows that mean rainfall have reduced during 1980-1989. The highest mean rainfall occurred in stations around Jos, Kaduna and Enugu in 1980-1989. Figure 1 shows that mean rainfall are normally distributed during 1990-1999. Highest mean rainfall occurred in Southern Guinea Savanna and. The mean rainfall is very high in Lokoja, and Enugu with values ranging from 2174 to $2987 \mathrm{~mm}$. The observation thus showed that during the second time slice, IIorin, Yola and Makurdi have the same value (550mm to $956 \mathrm{~mm}$ ) while Lokoja and Minna fall into the same group (1362 $\mathrm{mm}$ to $1768 \mathrm{~mm}$ ). These results confirmed that rainfall variability is higher in many stations in Northern Guinea Savanna than that of Southern. This confirmed that rainfall varies both spatially and temporally.

\subsection{Cassava Yield Variation as sensitivity to rainfall Variability}

Figures 2a, b, c and d show cassava yield variations as sensitivity to rainfall variability in Guinea Savanna part of Nigeria from 1970 to 2000. The figures are presented in form of time slices (decades) in relation with the rainfall variability per decade. Figures 2a, b and c show average cassava yield for three decades 1970-1979, 1980-1989 and 1990-2000 respectively while Figure $2 \mathrm{~d}$ represents average cassava yield for the periods between 1970 and 2000. Figure 2a shows that increase in cassava yield was recorded during the first time slice (1970-1979) and all stations also recorded major increase in the yield of cassava although the yield was high in the southern compared with that of the northern part. However, cassava yield was very bad during the second decade (1980-1989) especially in the northern part of the study area (Figure 2b). The result shows also that in Minna, Makurdi, Yola and Kaduna, the cassava yield were poor during the period of 1980 to 1989 (Figure 2b), but third decade (1990-2000) appears better compared with that of the second decade (1980-1989). Figure 2c depicts increase in cassava yield during 1990-2000 particularly in Shaki, Ilorin, Lokoja and Enugu. It was very clear in the maps that yields were in increase during the period of increase in rainfall (This is obvious in figure 2d). In general, the various results corroborate some of the earlier studies by scholars that rainfall is an important climatic element that determines whether cassava yield will be good or poor.

Table 1 depicts the result of correlation of cassava with monthly rainfall of growing season. Rainfall total for the growing season months (April to October) was correlated with the cassava yield. The results obtained showed that in most cases, there are no significant relationships between rainfall total and cassava yields in most of the stations. Except in Makurdi where April and May rainfall are significant with $\mathrm{R}=0.40(\alpha \prec 0.05)$ and 0.48 ( $\alpha \prec 0.01)$ respectively. Other relationships observed are statistically not significant. Correlation values are significant in June for Ilorin, April for Enugu and September for Jos. This actually means that cassava yields depend on rainfall in these months. The period of low yields are the years when rainfall variation was not in favour of cassava yield. In order to assess the cumulative effects of the growing season rainfall variability on cassava yield, total monthly rainfall of the growing season were correlated with the yield of cassava. The result of the cumulative correlation was evident under the column named "Total". It is observed that total rainfall of growing season is not significant in Makurdi, Yola, Minna and Lokoja. But, it is observed that the coefficient of correlation is significant with respect to total monthly rainfall of growing season for some stations, like Ilorin, Shaki, Enugu and Jos with $\mathrm{R}=0.32,0.38,0.38$ and 0.30 (Correlation is significant at $\alpha \prec 0.05$ ) respectively (Table 2). The result in Ilorin, Shaki, Enugu and Jos authenticate that rainfall of the growing season determines yield of cassava.

\subsection{Annual Impacts of Rainfall Variability on Cassava Yield}

Figure 3 shows cassava yield anomalies as response to rainfall variability for the whole study area. Figure 3 was derived from $\mathrm{z}$ - distribution result. It is obvious that $\mathrm{z}$ values are positive for 1970/1971 ( $\mathrm{z}=1.10), 1988 / 1989$ ( $\mathrm{z}$ $=1.09), 1989 / 1990(\mathrm{z}=3.21)$, and $1999 / 2000(\mathrm{z}=0.39)$. This in reality means that rainfall has positive impacts on the cassava yield. Negative impacts were noted for most of the years, especially, 1981/1982, 1982/1983, 1991/1992 and1998/1999. The results obtained confirmed the earlier findings of Adejuwon (2005) that rainfall does have impact on the crop yield during the growing season and that negative impacts were recorded during 1982/1983. Observation also shows that the time of planting influences the yield of cassava. For example, one 
may say that planting cassava at the onset of rain during the first decade (1970-1979) gave higher yield than late season planting during the second decade (1980-1989). This implies that the vegetative stage and tuber initiation of late planted cassava suffered severe stress due to termination of rainfall during the decade with inadequate rainfall in Guinea Savanna part of Nigeria because dry season is characterized by low soil moisture and high soil temperature. Water stress during root and tuber formation reduces the cassava yield drastically but, after seven months of planting, rainfall appears not to have significant or no influence on yield (Agbaje and Akinlosotu, 2004). This indicated that water stress at vegetative and growth stages rather than at post maturity stage causes lower yield in cassava. With the high cost of irrigation, introduction of drought resistant varieties for late season cultivation will be a viable option for improving the yield of cassava significantly among peasant farmers in Guinea Savanna part of Nigeria. This is in line with the observation of Agbaje and Akinlosotu (2004) that stated that the response of cassava to fertilizer will improve late season cultivation where a controlled irrigation system is used but the application of fertilizer to early-planted cassava will remain uneconomical and wasteful in season of excessive rainfall.

\subsection{Yam Yield Variation as sensitivity to rainfall Variability}

Figure 4 shows yam yield variation sensitivity to rainfall variability in Guinea Savanna part of Nigeria for the period of 1970 to 2000 . The result shows that yam yield increased during the first decade, that is, 1970 to 1979 . This is essentially true as a result of the adequate rainfall experienced during this period. This is evident on the map of rainfall variability. All the stations experienced quality yam yield during this period. The results obtained also showed that yam yield was very poor during the second decade (Figure $4 \mathrm{~b}$ ). The results are presented in dots maps. The dots in Figure 4a is more than that of Figure $4 \mathrm{~b}$ which implies that yam yield was very low during the period of 1980-1989. For instance, Shaki, Ilorin, Yola, and Lokoja have scanty dots (Figure 4b), which implies that the yield was actually poor during the second decade whereas high yield was recorded during the first decade and third decades. Table 2 shows the results of correlation of yam yield with monthly rainfall of the growing season. Rainfall total for the growing season months (April to October) was correlated with the yam yield. It is noted that correlation values are not significant for monthly total in almost all the stations except Enugu ( $\mathrm{R}=0.38, \alpha \prec 0.05)$. The correlation between yam yield and monthly rainfall of the growing season are not significant in most of the stations, except in Makurdi where April and May rainfall are significant with $\mathrm{R}=$ 0.43 and 0.44 respectively. Correlation values are significant in April for Enugu, June for Ilorin and August for Minna. The results obtained from correlation confirmed that yam yield in the study area is generally not significantly affected by rainfall variations (Table 2). The results obtained from some of the stations showed that correlation values are very low in the months of July, August, September and October with $\mathrm{R}<0.30(\alpha \prec 0.05$ or 0.01 ). The results actually suggest that rainfall of July, August, September and October did not contribute more than $30 \%$ to the yield of yam in all the stations. In Minna, Shaki, and Enugu for example, the correlation values for these months appeared very low ( $\mathrm{R}<0.30$, at $\alpha \prec 0.05$ and 0.01$)$. In order to assess the cumulative effects of the growing season rainfall variability on yam yield, total rainfall of the growing season was correlated with the yield. It is observed that the cumulative effects of the rainfall of growing season months are not significant in almost all the stations except in Enugu where $\mathrm{R}=0.38$ (at $\alpha \prec 0.05$ ). This actually means that variation in rainfall of Enugu has contributed greatly to the variation in yam yield in the station. The correlation results in other stations, however, are very low with $\mathrm{R}<0.30$ (Table 2 ). This essentially means that other factors contribute to the yield more than rainfall of the growing seasons in these stations.

\subsection{Annual Impacts of Rainfall Variability on Yam Yield}

Figure 5 shows yam yield anomalies as response to rainfall variability for the whole study area. It was obvious that during 1970/1971 $(Z-V a l u e=1.20), 1971 / 1972(Z$-Value $=1.30), 1989 / 1990(Z-V a l u e=1.44)$ and $1990 / 1991$ (Z-value $=1.82)$, the Z-distribution values are positive which means that rainfall has positive impacts on the yam yield during these periods in the whole areas. The results obtained revealed that negative impacts were prominent during 1981/1982 $(Z-$ Value $=-1.51)$ 1982/1983 $(Z$-Value $=-1.35), 1983 / 1984(Z-$ Value $=-1.52)$ $1992 / 1993(Z-V a l u e=-2.18)$. and $1993 / 1994(Z-V a l u e=-2.26)$. This implies that variation in rainfall during these years affected the yam yield adversely. It should be noted that the impacts are in two dimensions i.e. positive and negative impacts. With positive impact, it means that the rainfall during these periods (e.g. 1990/1991 with z-value of 1.81) has supportive impact on yam yield thereby facilitating increased yield. But negative impacts imply that the variations of rainfall lead to a decreased yield of yam.

\section{Conclusion}

The impacts of rainfall variability on the yield of selected tuber crops in Guinea Ecological Zone of Nigeria have been analyzed and mapped using Geographical Information Systems. Generally, some of the main findings in 
this study are related to its methodology. Results from the study revealed that GIS techniques proved efficient in assessing rainfall variability. Also, the results obtained from coefficient of variation revealed that rainfall variability is very high in most of Northern Guinea Savanna parts (e.g Yola, Minna, and Kaduna) with values of coefficient of variation between 26 and 49 percent while in Southern Guinea Savanna parts, the coefficient of variation is very low especially in Enugu (9\%) and Shaki $(8 \%)$. Therefore, it was found that rainfall varies both in time and space. It was observed that cumulative variation in rainfall truly influences yam and cassava yields during the second decade (1980-1989) leading to momentous reduction in the crop yield. The increase in yield recorded in 1990-2000 decade in all stations may perhaps be attributed to the increase in rainfall during the planting and growing seasons within the periods. But 1980-1989 experienced a very low rainfall during planting and growing seasons that had been due to a greater number of drought episodes. Probably, this may be due to the fact that agricultural productions are rain-fed and that about 95 percent of all cropland of this zone depends on rainfall as the sole source of water for crop yield. In these rain-dependent agro-ecosystems, the interaction of rainfall and other climatic elements determine the availability of water for crop yield. This study discovers that rainfall anomalies such as decline in annual rainfall, change in the peak, retreat of rainfall and false start of rainfall are detrimental to crop germination and yield, resulting in little or no harvest at the end of the season. With the foregoing in mind, the key question now is "what can be done to achieve an increase in crop yield despite variation in rainfall pattern?" Based on the findings above and the practicable conclusion of this study, the following recommendations are suggested in order to put the research work in proper implementation. (1) That agro-climatological research should be encouraged to improve crop yields. Such research needs to address a means of improving crop yield in the present and in the future when the rainfall conditions may be less favourable for agricultural purposes; (2) Also, agricultural reform should be implemented to enhance infrastructure investment in Nigeria; (3) more so, government should invest in future water supply expansion and efficiency enhancement through modern day irrigation systems; and (4) farming techniques need to be improved in the study area.

\section{References}

Adejuwon, J.O. (2005). Food Crop Production in Nigeria: Present effects of Climate Variability. Climate Research, inter-Research, Germany, 30, P.53-60.

Adejuwon, J.O., \& Odekunle T.O. (2006). Variability and the Severity of the "little Dry Season" in southwestern Nigeria. American Meteorogical Society, 19, P.483-493.

Agbaje G.L., \& Akinlosotu T.A. (2004). Influence of NPK Fertilizer on Tuber Yield of Early and Late-planted Cassava in a Forest Alfsoil of Southwestern Nigeria. African Journal of Biotechnology, 3 (10), P. 547-551.

Buchanan, K.M., \& Pugh, J.C. (1955). Land and People in Nigeria. University of London Press Ltd, Warwick square, London, E.C.4, P.28.

FAO. (2001). Climate Variability and Change: A Challenge for Sustainable Agricultural Production. Committee on Agriculture. P.56

FAO. (2002a). FAO Quarterly Bulletin of Statistics, 4(4); 24 and 53.

FAO. (2002b). The Salt of the Earth; Hazardous for Food Production. World Food Summit; Five Years Later. [Online] Available: http//www.fao.org/worldfoodsummit/English/newsroom/focus/focus1.html>

Haimson, L. \& Ennis, C. (2004). Common Questions About Climate Change. Sponsored by UNEP/WHO. P.25

IPCC. (2000). Good Practice Guidance and Uncertainty Management in National Greenhouse Gas Invetories. The Intergovernmental Panel on Climate Change (IPCC) Working Group I, National GHG Invenories programme, IGES, Hayama, Kanagawa, Japanhe Regional Impacts of Climate Change: An Assessment of Vulnerability, P.35.

IPCC. (2002). Climate Change 2001: Synthesis Report. A contribution of working Group I, II and III to the Third Assessment Report of the Intergovernmental Panel on Climate Change (Watson, R.T, et al \{eds\}). Cambridge University Press, Cambridge, UK. P. 239-397.

Stern, R.D., \& Coe, R. (1982). The use of rainfall models in agricultural planning. Agric. Meteorol, 26, P. 35-50. 
Table 1. Result of Coefficient of Variation and Correlation of Cassava with Growing Season Rainfall

\begin{tabular}{|lllllllllll|}
\hline \multirow{2}{*}{ Stations } & \multicolumn{7}{c}{ Correlation of Cassava yield with Growing Season Rainfall } \\
& TOTAL & APR & MAY & JUNE & JULY & AUG & SEPT & OCT \\
ENUGU & $0.380^{*}$ & $0.382^{*}$ & 0.034 & 0.178 & 0.032 & 0.091 & 0.295 & 0.274 \\
ILORIN & $0.318^{*}$ & 0.149 & 0.284 & $0.399^{* *}$ & 0.244 & 0.082 & 0.024 & 0.092 \\
JOS & $0.303^{*}$ & 0.071 & 0.117 & 0.005 & 0.088 & 0.259 & $0.407 *$ & 0.172 \\
KADUNA & 0.049 & 0.234 & 0.140 & 0.248 & 0.045 & -0.307 & -0.144 & 0.212 \\
LOKOJA & 0.025 & 0.050 & 0.024 & 0.140 & 0.012 & 0.256 & 0.239 & 0.135 \\
MAKURDI & 0.205 & $0.400^{*}$ & $0.482 * *$ & -0.344 & 0.242 & -0.012 & 0.132 & 0.219 \\
MINNA & 0.021 & 0.072 & 0.048 & 0.103 & 0.218 & -0.219 & 0.227 & 0.111 \\
SHAKI & $0.379 *$ & 0.056 & 0.136 & 0.032 & 0.111 & 0.211 & 0.345 & 0.270 \\
YOLA & 0.034 & 0.060 & 0.167 & 0.073 & 0.146 & 0.305 & 0.093 & -0.174 \\
\hline
\end{tabular}

**Correlation is significant at $\alpha \prec 0.01$

*Correlation is significant at $\alpha \prec 0.05$

Dependent variable $\mathrm{y}$ is cassava yield while explanatory variable $\mathrm{x}$ is rainfall

Table 2. Result of Coefficient of Variation and Correlation of Yam with Growing Season Rainfall

\begin{tabular}{|llllllllll|}
\hline Stations & \multicolumn{7}{c}{ Correlation of Yam yield with Growing Season Rainfall } \\
& TOTAL & APR & MAY & JUNE & JULY & AUG & SEPT & OCT \\
ENUGU & $0.380^{*}$ & $0.382^{*}$ & 0.034 & 0.179 & 0.032 & 0.091 & 0.295 & 0.273 \\
ILORIN & 0.286 & 0.105 & 0.129 & $0.516^{*}$ & 0.190 & 0.077 & -0.210 & 0.070 \\
JOS & 0.030 & 0.093 & 0.172 & 0.227 & -0.140 & -0.346 & -0.071 & 0.206 \\
KADUNA & 0.134 & 0.136 & 0.236 & 0.313 & 0.080 & 0.193 & 0.227 & 0.286 \\
LOKOJA & 0.043 & 0.093 & -0.010 & 0.103 & 0.011 & 0.145 & 0.241 & 0.078 \\
MAKURDI & 0.170 & $0.426^{*}$ & $0.436^{* *}$ & -0.344 & 0.253 & -0.101 & 0.180 & 0.244 \\
MINNA & 0.046 & 0.192 & 0.076 & 0.102 & 0.097 & $0.367 *$ & 0,063 & 0.061 \\
SHAKI & 0.151 & 0.024 & -0.134 & 0.003 & 0.077 & -0.172 & -0.235 & 0.150 \\
YOLA & 0.014 & 0.186 & 0.122 & 0.008 & 0.162 & -0253 & 0.088 & -0.221 \\
\hline
\end{tabular}

**Correlation is significant at $\alpha \prec 0.01$

*Correlation is significant at $\alpha \prec 0.05$

Dependent variable $\mathrm{y}$ is yam yield while explanatory variable $\mathrm{x}$ is rainfall 


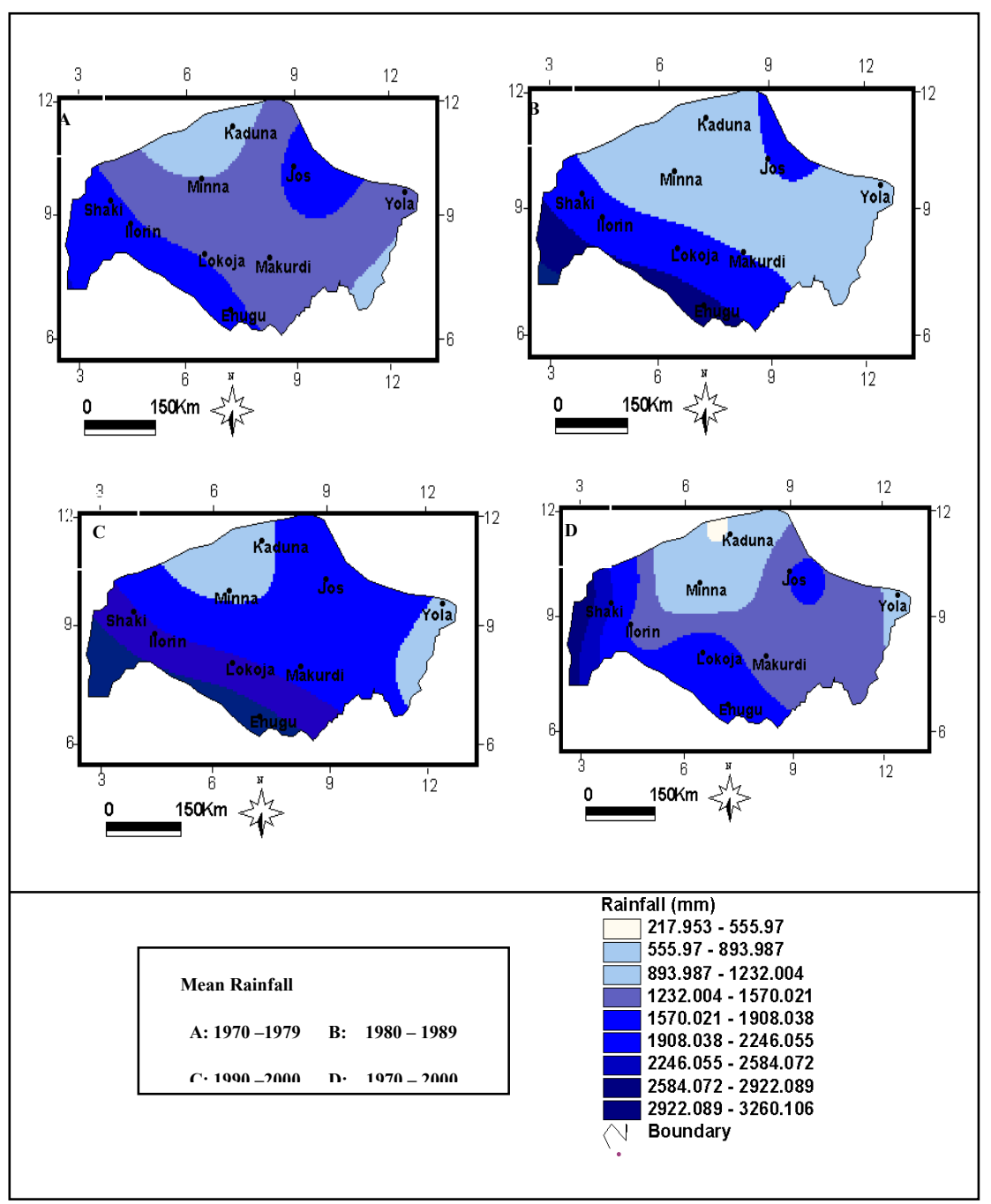

Figure 1. Rainfall Variability per Decade in Guinea Savanna part of Nigeria (1970 to 2000) 


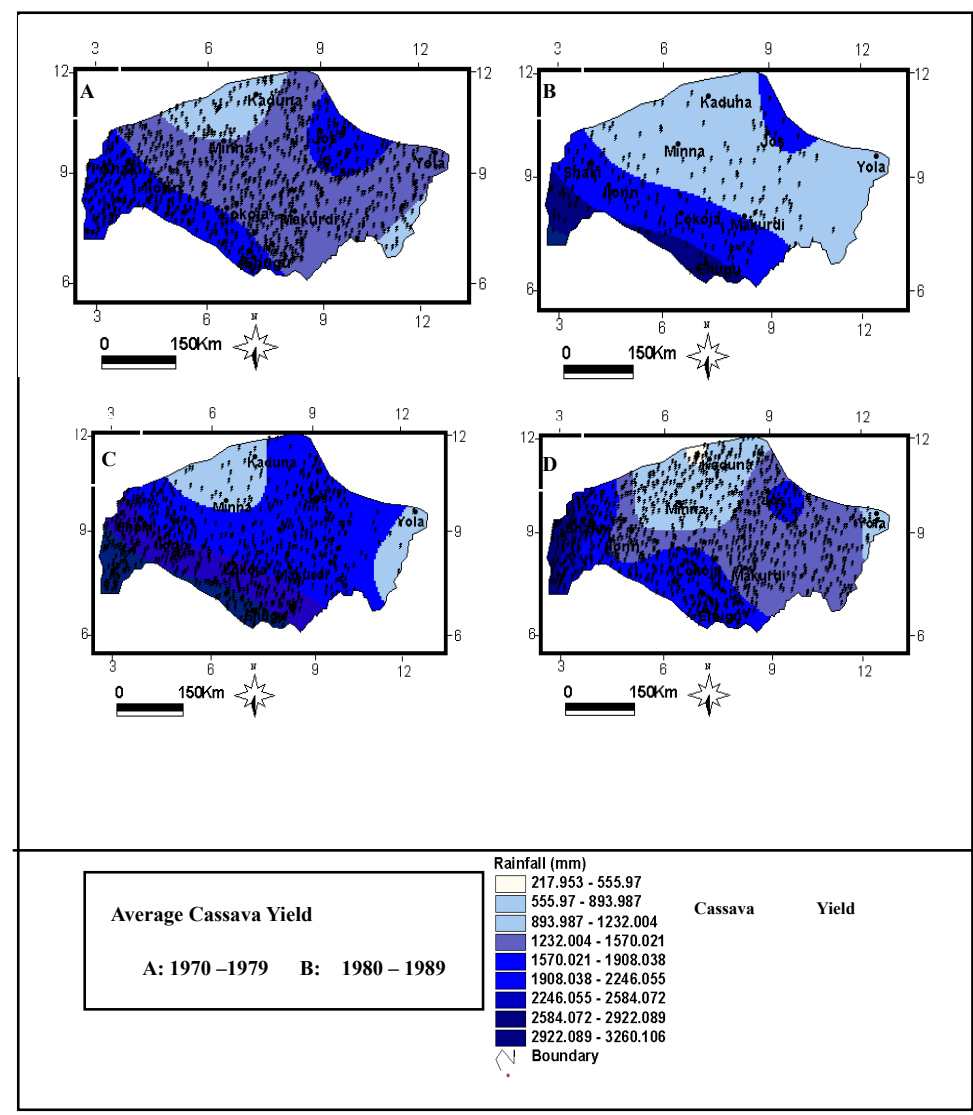

Figure 2. Cassava Yield Variations: Sensitivity to Rainfall Variability in Guinea Savanna part of Nigeria (1970 to 2000)

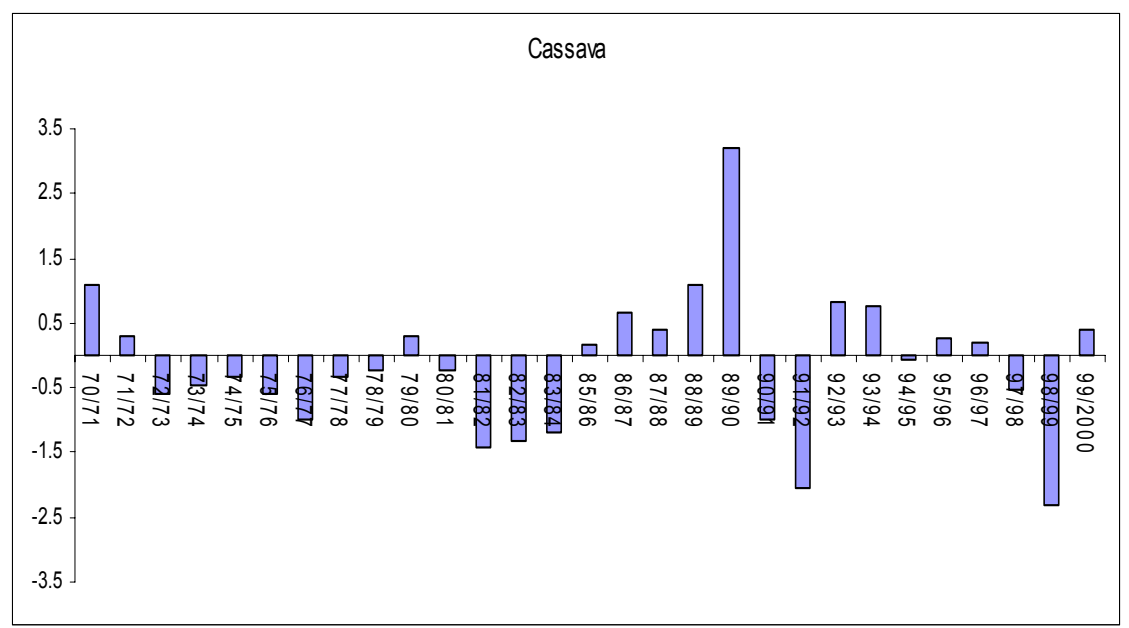

Figure 3. Cassava Yield Anomalies; Responses to Rainfall Variability for Guinea Savanna part of Nigeria 


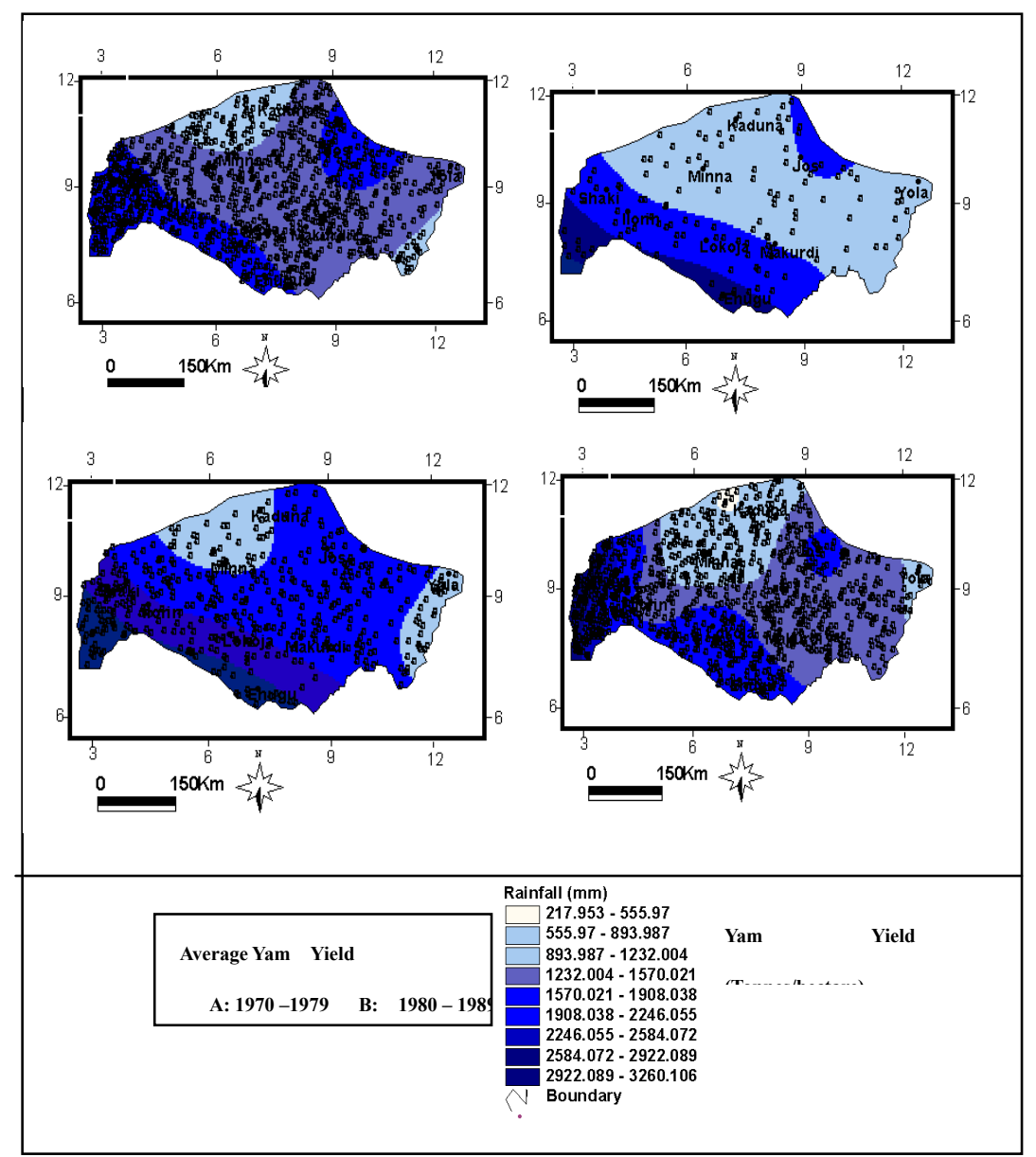

Figure 4. Yam Yield Variations: Sensitivity to Rainfall Variability in Guinea Savanna part of Nigeria (1970 to 2000)

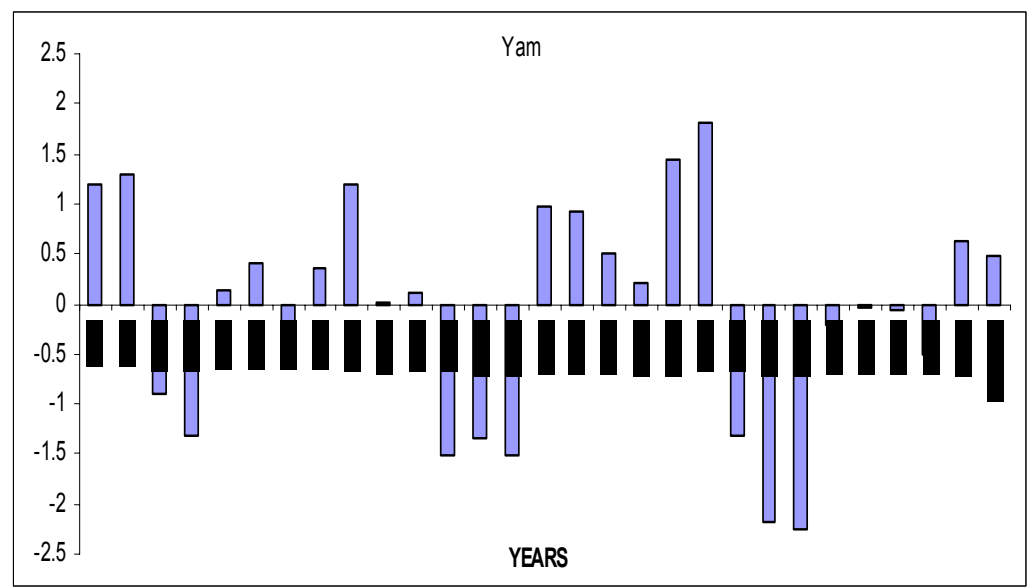

Figure 5. Yam Yield Anomalies; Responses to Rainfall Variability for Guinea Savanna part of Nigeria 